\title{
Application of Green Technology Using Biological Means for the Adsorption of Micro-Pollutants in Water
}

\author{
Tanimola Hamed ${ }^{1}$, Owolabi John², Awoyemi Emmanuel ${ }^{3}$, Kayode Benjamin ${ }^{4}$ \\ ${ }^{1}$ Department of Chemical Engineering, University of Ilorin, Ilorin, Nigeria \\ ${ }^{2}$ Waste Water and Environmental Engineering, University of Greenwich, London, UK \\ ${ }^{3}$ Ladoke Akintola University of Technology, Ogbomosho, Nigeria \\ ${ }^{4}$ Mega Sustainable Integrated Resources Limited, Lagos, Nigeria \\ Email: tanimolatobi@yahoo.com
}

How to cite this paper: Hamed, T., John, O., Emmanuel, A. and Benjamin, K. (2020) Application of Green Technology Using Biological Means for the Adsorption of Micro-Pollutants in Water. Journal of Environmental Protection, 11, 735-752. https://doi.org/10.4236/jep.2020.119045

Received: July 25, 2020

Accepted: September 11, 2020

Published: September 14, 2020

Copyright (c) 2020 by author(s) and Scientific Research Publishing Inc. This work is licensed under the Creative Commons Attribution International License (CC BY 4.0).

http://creativecommons.org/licenses/by/4.0/

\begin{abstract}
It is true that the world we have today is not the world we use to know. The Covid-19 pandemic has paralyzed all sector, hence the need for safety and enabling environment for mankind is of high importance. Adsorption technology is far the best and cheapest treatment technology for water and has extensively proven its worth for the uptake of micro-pollutant from surface, ground and water which are the major channels of home water. Over the years activated carbon is considered as the most common and universally used adsorbent for the eradication of different types of micro-pollutants from water. The contamination of surface water by micro-pollutant is a potential threat for the production of high quality and safe drinking water. Adsorption operation onto granulated activated carbon (GAC) in fixed-bed filters is often applied as a remedying step in the synthesis of safe and drinkable water. Activated carbon actively tends to act as a carrier material for a thin usually resistant layer of microorganisms (mostly bacteria) that forms on the coat of various surfaces (biofilm), hence biological simplification can be an alternative removal approach that can be adopted in granulated activated carbon filters. To evaluate the capacity of biofilm to biologically simplify micro-pollutants, it is very imperative to distinguish adsorption from biological simplification (biodegradation) as a removal mechanism. Experiment was carried out under the operating condition of a temperature range of $6^{\circ} \mathrm{C}$ to $20^{\circ} \mathrm{C}$ with biologically activated and autoclaved GAC to assess the biological simplification by the biofilm adsorbed on the GAC surface. Five micro-pollutants were selected as model compounds, of which some of them were biologically simplified by the GAC biofilm. Additionally, we observed that temperature can increase or decrease adsorption. Conclusively, comparison was made on the adsorption
\end{abstract}


capacity of granulated activated carbon used for more than 50,000 beds.

\section{Graphical Abstract}

\section{GAC filter - drinking water production}

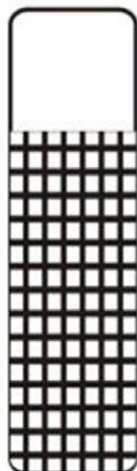

$20^{\circ} \mathrm{C}$
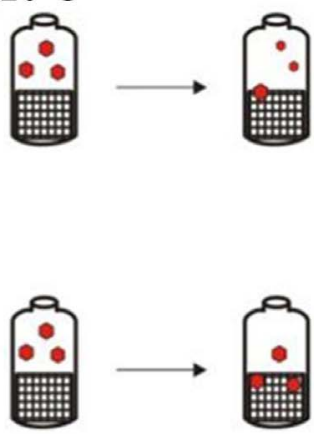

$6^{\circ} \mathrm{C}$
Adsorption and Biodegradation

Organic micropollutants

\section{Keywords}

Green Technology, Micro-Pollutants Removal, Adsorption through Activated Carbon, Water Treatment, Biodegradation and Biological Means,

Temperature Effect

\section{Introduction}

Basically, organic micro-pollutants resulting from the influence of human beings on nature have been detected in surface water worldwide and thus posing a threat to the production of safe drinking water. Micro-pollutants encompass a broad range of compounds, such as insecticides, herbicides, fungicides, pharmaceuticals, industrial chemicals, pesticides, as well as the products to which they are converted into. These chemical species frequently enter into the human immediate environment via the effluent of a wastewater treatment plant (WWTP) and diffuse sources, such as storm water runoff, sewer leakage and sewer overflow. Micro-pollutants whose composition is not known in the environment are adsorbed to precipitate or living matter, it is otherwise converted through reactions involving living and non-living organisms. The content of the composition that is left over, can end up in the feed water supplied for drinking water production [1].

Furthermore, micro-pollutants are partly taken off from the surface water source in a drinkable water treatment plant through adsorption onto granulated activated carbon (GAC) in fixed bed filters. Granulated activated carbon has also been applied at pilot scale in filters and fluidized bed reactors for the removal of micro-pollutants from wastewater [2] [3]. Excluding the adsorbing potential of the micro-pollutants, granulated activated carbon (GAC) can otherwise be used 
as a carrier material for biofilm. Due to this, micro-pollutants are concentrated on the granulated activated carbon (GAC) surface, and hence resulting in an increment in the contact time between the microorganisms and compounds [4], and enhanced probability of biological simplification, that is biodegradation.

Therefore, biological simplification is another method that can be adopted in the removal of micro-pollutants from granulated activated carbon (GAC) application. The degree at which individual micro-pollutant was adsorbed to granulated activated carbon (GAC) and ultimately be biodegraded depends on the reversibility of adsorption and on the tendency of the biofilm to biodegrade the micro-pollutant.

To make pointing distinction between adsorption and biodegradation as suitable removal techniques to be adopted, in the granulated activated carbon filter, the granulated activated carbon filter is expected to assess the strength and activity of the biofilm in it as well as its effectiveness in micro-pollutants degradation. More so, checking into the limitation of the action of the granulated activated carbon filter in micro-pollutant degradation is very imperative in this study. Adsorption studies with freshly synthesized granulated activated carbon (GAC), showed that estimating the quantity of certain adsorbed adsorbate calculations is based on the changes in concentration that occurs in the liquid phase of the adsorption media, if adsorption technique is the taken as the only removal method [5]. During analytical experimentation with biologically active granulated activated carbon (bGAC), it was observed that the adsorbate cannot only be adsorbed but also biodegradable. Although slowing down the activity of biodegradation, by putting into consideration granulated activated carbon treatment techniques, such as addition of chemicals to the solution mixture so as to alter adsorption rate to a considerable extent and also by autoclaving the reaction system. A very common biodegrading agent that slows biodegradation activity over adsorption is sodium azide [6]. Nevertheless, sodium azide alters adsorption activity, as demonstrated by [7] who examined the impact of this chemical on the removal of fulvic acids by activated carbon (AC). A conclusion was drawn by the authors that the sodium azide did not totally slow down the biological activity and also that it reacted with the activated carbon (AC) surface thus changing its adsorption characteristics. In addition to chemically affected activated carbon (AC), autoclaved used activated carbon (AC) might have different adsorption properties compared with non-autoclaved (activated carbon) AC, because autoclaving can potentially alter the biofilm formed on the AC surface and the organic matter previously adsorbed to it, thus affecting micro-pollutants adsorption.

Moreover, adsorption and biodegradation can otherwise be differentiated, by making experimental analysis with biologically active granulated activated carbon (GAC) at very high and mild temperature, for the remediation of micro-pollutants in water. Raising the temperature to a certain limit of about $43^{\circ} \mathrm{C}$ tends to enhance increment in microbial activity. However, temperature effects on adsorption are less predictable. Additionally, the overall equilibrium adsorption condi- 
tion and adsorption rate can be affected by temperature. Therefore, raising the temperature improves the adsorbate diffusion onto the adsorbent which in turn produce a higher adsorption rate [8] though, the overall adsorption capacity can either be increased or reduced [9], depending on whether the adsorption occurs through an endothermic operation process or exothermic method of operation [10].

Considering the challenge to differentiate between adsorption and biodegradation as micro-pollutants removal operations, very few studies have estimated the micro-pollutant biodegradation ability of biomass growing in granulated activated carbon (GAC) filter adopted in drinkable water treatment plant DWTP [1] [11]. The differences in biodegradation of micro-pollutants by activated ooze from waste water treatment plants (WWTP) are well documented in literature [12]. The objective of this research is to investigate if the biomass growing in granulated activated carbon filters is capable of degrading a selection of micro-pollutants relevant for drinking water. Studies were carried out on the removal of micro-pollutants with activated carbon that originates from a drinking water production location. Experimental analysis with biologically active or autoclaved granulated activated carbon at two different temperatures was performed to distinguish removal due to adsorption and biodegradation or adsorption only.

\section{Materials and Methods}

\subsection{Organic Micro-Pollutants}

At the preliminary stage of the methodology, carefully mixed solution of the micro pollutants; benziotriazole, diclofenac, melamine, metformin, Iopromide, Iopamidol and guanylurea were purchased at Boluke Pharmacy, Agege, Lagos. These organic micro-pollutants have been found mostly in surface water in small quantity ranging from $0.15 \mu \mathrm{g} / \mathrm{l}$ to $7 \mu \mathrm{m} / \mathrm{l}$ and are relevant in water treatment.

A pH meter was used to check the $\mathrm{pH}$, all the five micro pollutants had a neutral charge of $\mathrm{pH} 7.52$, except for metformin and pyrazole, which are positively charged and diclofenac which is negatively charged.

\subsection{Micro-Pollutants Disintegration by Biologically Active Granulated Activated Carbon (GAC)}

A batch experiment approach was used since the target here is to assess the potential of biofilm growth in granulated activated carbon (GAC) filters to DWTP. The filter where the used GAC was collected had been in operation for years, more than 100,000 bed volumes by Tom Water Company (location Iju Ifako Ijaiye, Lagos Nigeria). This material will be referred to as biological granulated activated carbon (bGAC). The biologically granulated activated carbon (bGAC) worked both as adsorbent and inoculum. To supply microorganisms with additional carbon source similar to what is available in the GAC filters, the culture media was prepared using GAC filter influent, obtained from the same DWTP as 
the biological granulated activated carbon (bGAC), and demineralized water, in a 1:1 ratio. Concentrated nutrient solutions were diluted in this matrix. Demineralized water was used together with GAC filter influent was used to prepare the culture media obtained from the same DWTP as the biological granulated activated carbon (bGAC), and demineralized water in an empirical ratio 1:1 to avoid high concentration of salt in the culture media, that could harbor microbial activity; demineralized water was used together with GAC filter. Additional inoculum was prepared: $15 \mathrm{~g}$ of granulated activated carbon was mixed with 20 $\mathrm{ml}$ of culture media and whirl pooled for 5 seconds. The step was repeated up to five (5) times to achieve liquid phase at biomass level.

A wet mass of $0.35 \mathrm{~g}$ of the bGAC corresponding to approximately $0.1 \mathrm{~g}$ dry weight was utilized to inoculate $250 \mathrm{ml}$ serum bottles $10 \mathrm{ml}$ of extra inoculum cultured media in a total liquid and micro-pollutant. These similar molar concentration $\left(\mathrm{mol} / \mathrm{dm}^{3}\right)$ were used, $\left(260 \mu \mathrm{mol} / \mathrm{dm}^{3}\right), 47 \mu \mathrm{mol} / \mathrm{dm}^{3}$ and 67 $\mu \mathrm{mol} / \mathrm{dm}^{3}$ ranging from $1.6-53.8 \mathrm{mg} / \mathrm{L}$; which depends on the micro-pollutant. Initial micro-pollutants concentrations were measured, the initial concentration were the sum of the spiked and the already present micro-pollutant (if any), aluminium foil was used to prevent micro-pollutants photo degradation and cultivated as either $6^{\circ} \mathrm{C}$ or $21^{\circ} \mathrm{C}$ at a 120 revs/min. samples were taken periodically $0,9,21,33,44$ and 59. Samples were placed in a centrifuge and centrifuged for $10 \mathrm{mins}$ at $10,000 \mathrm{rev} / \mathrm{min}$, the supernatant was transferred to a clean clear tube and again centrifuged. Then the supernatant was diluted, frozen and kept for analysis. After washing up to day 59 the result was sufficient to test our hypothesis and draw inference and conclusion, then the experiment was halted.

\subsection{The Adsorbed Micro-Pollutants onto Autoclaved Used GAC}

The adsorbed micro-pollutants onto the granulated activated carbon (GAC) was processed in a test with autoclave using the granulated activated carbon (GAC) to check the effect of the temperature with autoclave granulated activated carbon (GAC) no biodegradation was expected but we expect little variation between replicates, which indeed was observed in our data, so that only the duplicates were re-run. The experiment which was carried out with one initial concentration of micro-pollutants (approximately $70 \mu \mathrm{M}$ diagram below). The bottles were cultivated in the same condition as in experiment 2.2 above.

\subsection{Adsorbed Micro-Pollutants onto Fresh GAC}

This experiment is necessary so as to compare the adsorption capacity of experiment in 2.3 (used GAC) and the new experiment onto fresh GAC. The following are exception to the comparison.

1) Newly prepared GAC was used instead of used GAC;

2) Water was partly used in the preparing the media other than the mixture of the partly used water with GAC filter influent;

3) $62 \mu \mathrm{M}$, that is one initial concentration of micro-pollutant was used other 
than three (3). The bottles were kept at $6^{\circ} \mathrm{C}$ and mixed at $130 \mathrm{rpm}$. The samples for days zero (0) and day nine (9) were studied and it showed that this time interval is sufficient for fresh granulated activated carbon (GAC) to near equilibrium conditions for the selected micro-pollutant adsorbed [13].

Figure 1 shows a schematic representation of experiments with used GAC $\left(6^{\circ} \mathrm{C}\right.$ and $\left.20^{\circ} \mathrm{C}\right)$

\subsection{Chemical Analyses}

Liquid chromatography was used to measure the micro-pollutants coupled to high resolution accuracy of the mass spectrometry. In summary, Atlantis T3 was used to separate compounds and gradient water/ammonium formate base 2 $\mathrm{mm} /$ formic acid $0.018 \%(\mathrm{v} / \mathrm{v}$ ) and methanol/ammonium formate $2 \mathrm{~mm} /$ formic acid $0.018 \%(\mathrm{v} / \mathrm{v})$ the resolution for the analysis was 70,000 and was carried out in positive electrospray ionization mode upon a Thermo Q Exactive MS in full-scan mode.

\section{Results and Discussion}

\subsection{The Unique Differences in Micro-Pollutants Adsorption and Biodegradation}

Experimental operation carried out with the biologically active granulated activated carbon (bGAC) and the autoclaved granulated activated carbon at varying temperature in other to access if the biofilm from the GAC filter can biologically breakdown (biodegrade) the selected set of micro-pollutants. Micro-pollutants removal mainly if a low temperature operating condition is assumed as this basically serves as a control method. On the account of observing the effects of temperature during the process of micro-pollutants on adsorption rate, experiment was performed so as to estimate the effects of temperature on adsorption.

The removal of iopromide using biologically active granulated activated carbon (bGAC) apparently remains unchanged until the 9th day with operation performed at a temperature range of $6^{\circ} \mathrm{C}-20^{\circ} \mathrm{C}$, as shown in (Figure $2(\mathrm{a})$ ). the difference that arises in the extent of removal at varying different temperature were observed after this period. Over $99 \%$ of iopromide was removed at $20^{\circ} \mathrm{C}$ irrespective of the fresh feed concentration in the period of 54 days, such that the residual iopromide concentration was below $0.48 \mu \mathrm{M}$. However, a removal variation ranges between $50 \%$ and $92 \%$ were observed at $6^{\circ} \mathrm{C}$, and this depends upon the initial amount of the fresh feed iopromide (Figure 2(a)). Also, the removal of iopromide with both biologically active granulated activated carbon (bGAC) and autoclaved granulated activated carbon showed a correlating activity (Figure 2).

Experimental observation and result with autoclaved GAC show that the adsorption activity of iopromide has a positive and direct relationship with temperature rise (Figure 2(b)). Generally, temperature varies directly with rate of 


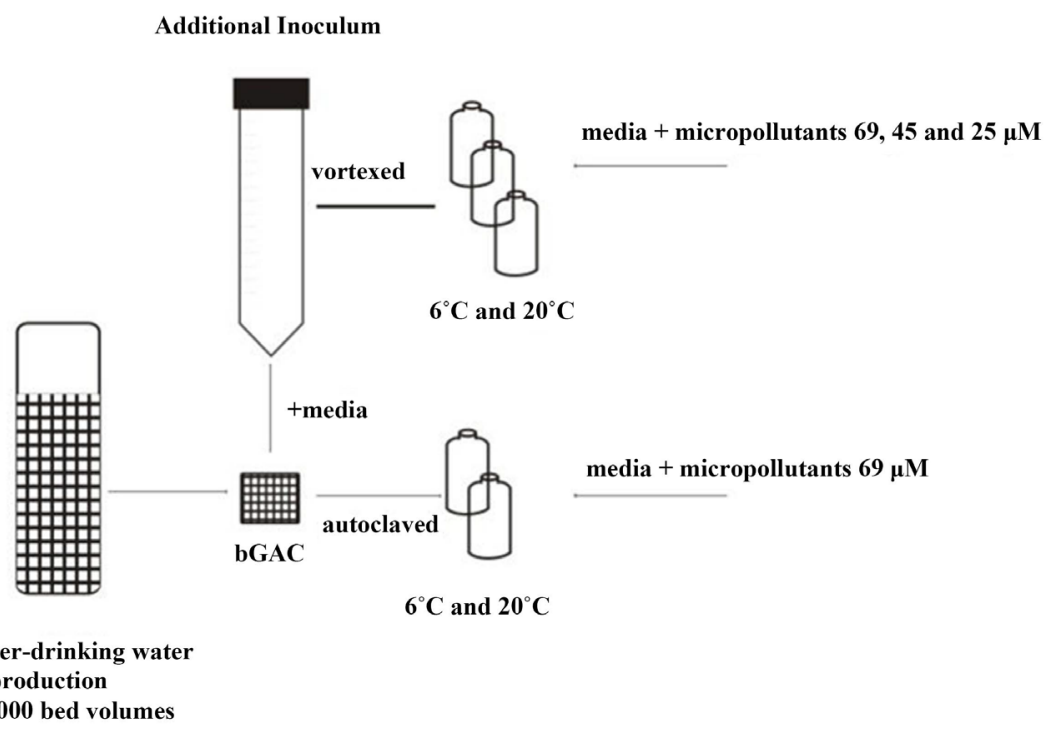

Figure 1. Schematic representation of experiments with used GAC.
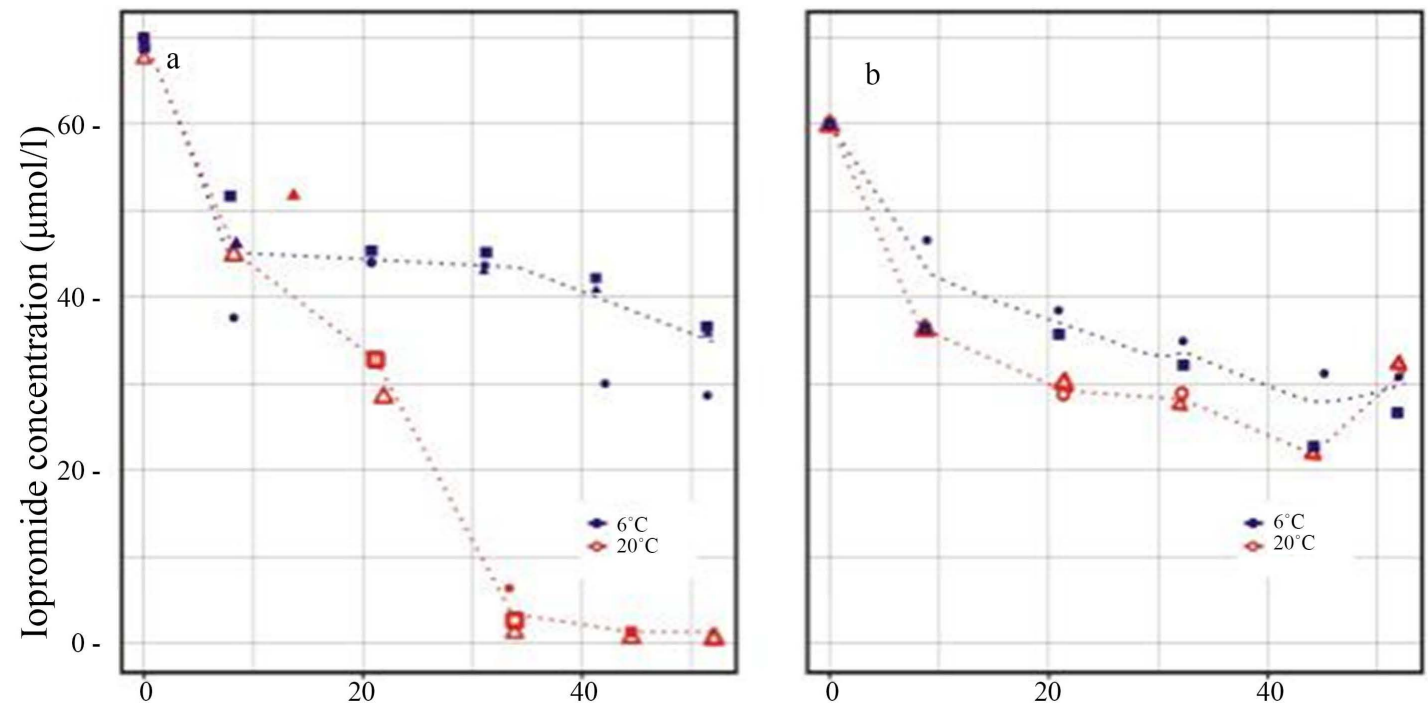

Time (d)

Figure 2. Iopromide concentration in time at $6^{\circ} \mathrm{C}$ and $20^{\circ} \mathrm{C}$ with bGAC (a) and autoclaved GAC (b). Different symbols represent different replicates of the same treatment. Lines connect the mean value of replicates in each time point.

diffusion and diffusion in the long run has a limiting effect on adsorption [14]. Although, this does not account for the increased iopromide adsorption at $20^{\circ} \mathrm{C}$, as at both temperature rate of adsorption virtually remains unchanged. These results and data obtained from experimental analysis gives evidence and shows adsorption iopromide is simply exothermic in nature and studies on the exothermic adsorption of compounds like ibuprofen and rhodamine shows that these compounds adsorption is characterized by the production of adsorption sites at higher temperature, this analysis, thus shows biodegradation is very important removal mechanism with biologically active granulated activated carbon 
(bGAC) and autoclaved granulated activated carbon (GAC).

Over 50\% removal of iopromide was observed biologically active granulated activated carbon (bGAC) filter treating secondary discharge or effluents from a waste water treatment plant (WWTP). This goes in accordance with the report in the literature review proposed by [15]. Stability was achieved in removal rate even after a prolonged operation (30,000 bed volumes was related to iopromide adsorption and biodegradation. An approximate amount of about $60 \%$ iopromide removal of micro-pollutants from biologically active granulated activated carbon (bGAC) filter was reported according to [16]. Therefore, biodegradation serves as a very suitable micro-pollutants removal mechanism according to these authors hypothesis as looking into the ages of the biologically active granulated activated carbon (bGAC) 2 years and the quantity of organic matter around 2 $\mathrm{mg} / \mathrm{L}$ available in the influents. This study however helps to also account for evidence that iopromide can be degraded by biomass growing in biologically active granulated activated carbon (bGAC) filter.

Biodegradation of iopromide can give rise to refractory change over products and full mineralization has not yet been reported [17]. Experimental analysis with biologically active granulated activated carbon (bGAC) shows that peaks with identical exact mass (within $6 \mathrm{ppm}$ ) and isotope pattern in line with 3 iopromide biodegradation products as given by [18]. This iopromide degradation product detected gives additional evidence and supports of suitability of iopromide biodegradation.

Metformin was biodegraded at $20^{\circ} \mathrm{C}$ with biologically active granulated activated carbon (bGAC) in a way akin to iopromide as shown in the diagram. At the initial stage of the process, the removal of metformin was very high during the experiment at $6^{\circ} \mathrm{C}$ than at $20^{\circ} \mathrm{C}(34 \%$ and $22 \%$ average removal on day 9 at $6^{\circ} \mathrm{C}$ and $20^{\circ} \mathrm{C}$ respectively), from this, deduction was drawn that metformin adsorption, is an exothermic process. The lowest initial concentration of quality $(26 \mu \mathrm{M})$ has a use up period of 9 days an intermediate use up period of 12 days and same for that of the highest, initial concentration with quality of $46 \mu \mathrm{M}$ and 70 $\mu \mathrm{M}$ respectively. Metformin biodegradation was discerned in 7 out of 9 bottles at the operating temperature of $20^{\circ} \mathrm{C}$ also the removal if metformin was noticed to be greater than $99 \%$ as at day 33 , this was the observation deduced after the initial phase analysis and this result were independent of initial concentration. More so, metformin biodegradation at $20^{\circ} \mathrm{C}$ shows more evidence of proves based on its production of its first product of degradation guanylurea as shown in (Figure 3(a)) During experimental analysis the concentration of guanylurea increases in all cases accompanied by biodegradation. Experiments with autoclaved granulated activated carbon(GAC) proved vital that the removal of micro-pollutant metformin is $26 \%$ at $6^{\circ} \mathrm{C}$ and $17 \%$ at $20^{\circ} \mathrm{C}$ and guanylurea is $89 \%$ at $6^{\circ} \mathrm{C}$ and $81 \%$ at $20^{\circ} \mathrm{C}$, hence showing that the removal of metformin and guanylurea at $6^{\circ} \mathrm{C}$ were higher and to a greater extent than at $20^{\circ} \mathrm{C}$. Referencing the observation deduced during the first day of analysis with biologically active granulated activated carbon (bGAC) as shown in (Figure 3), it's obvious and very imperative to 

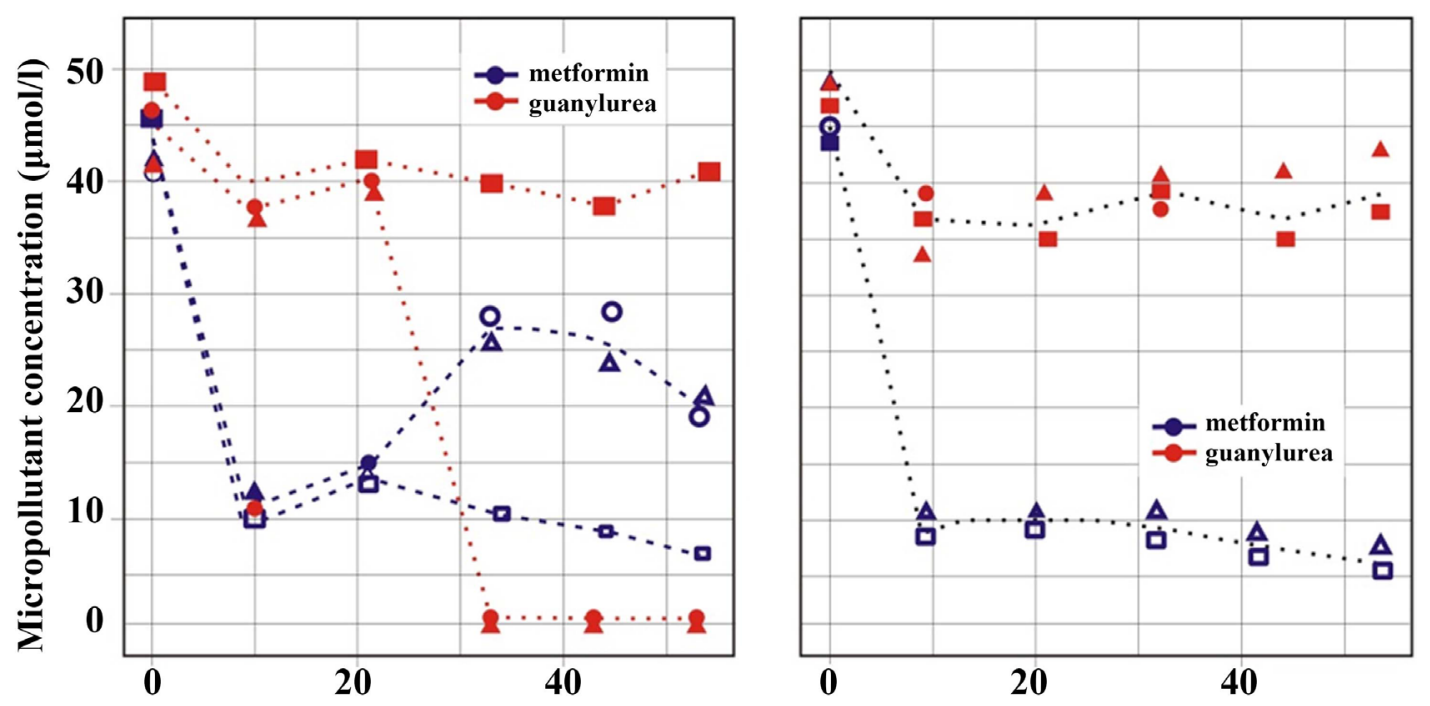

Time (d)

Figure 3. Metformin and guanylurea concentration in time at $20^{\circ} \mathrm{C}$ (a) and $6^{\circ} \mathrm{C}$ (b) in experiment with bGAC. Different symbols represent different replicates of the same treatment. Lines connect the mean value of replicates in each time point.

conclude that metformin and guanylurea adsorption is exothermic.

Also, further removal of guanylurea synthesized was aided by either biodegradation or adsorption. Although, the removed guanylurea between day 33 and day 54 cannot be clarified through adsorption alone (Figure 3(a)). Initially adsorption rate was faster and it slows down with time, but experimental result obtained has an inverse trend with this as the initial removal rate of guanylurea is lower (between day 33 and day 44), however rises significantly between day 44 and day 54, this trend is less regular with removal due to adsorption as compared to removal due to biodegradation [19]. Also, at the initial stage, the dead end metformin biodegradation product has been described as guanylurea [20]. Even though recent studies have accounted that the biodegradation of guanylurea by activated sludge or culture enriched from activated sludge [21] [22] [23], thus showing the consistency and correlation of our experimental observation with guanylurea biodegradation.

The biodegradation of metformin and production guanylurea were not observed in all duplicate experimental procedures, only 3 duplicate metformin biodegradation with initial concentration of $26 \mu \mathrm{M}$ shows the production of guanylurea from metformin biodegradation considering (Figure 3(a)), however, only 2 of 3 duplicate with initial concentration of $46 \mu \mathrm{M}$ and 1 of the 3 duplicate with initial concentration of $70 \mu \mathrm{M}$. Hence, duplicate with operating temperature of $20^{\circ} \mathrm{C}$ where there was no biodegradation of metformin was extracted during the mathematical procedure for graphing figures. Variation was observed between duplicate on performing an independent experiment which goes in relation with the conditions described in 2.2 and 2.3 above as during experiment there was metformin degradation in 2 out of 3 replicate (Figure 4 ). 


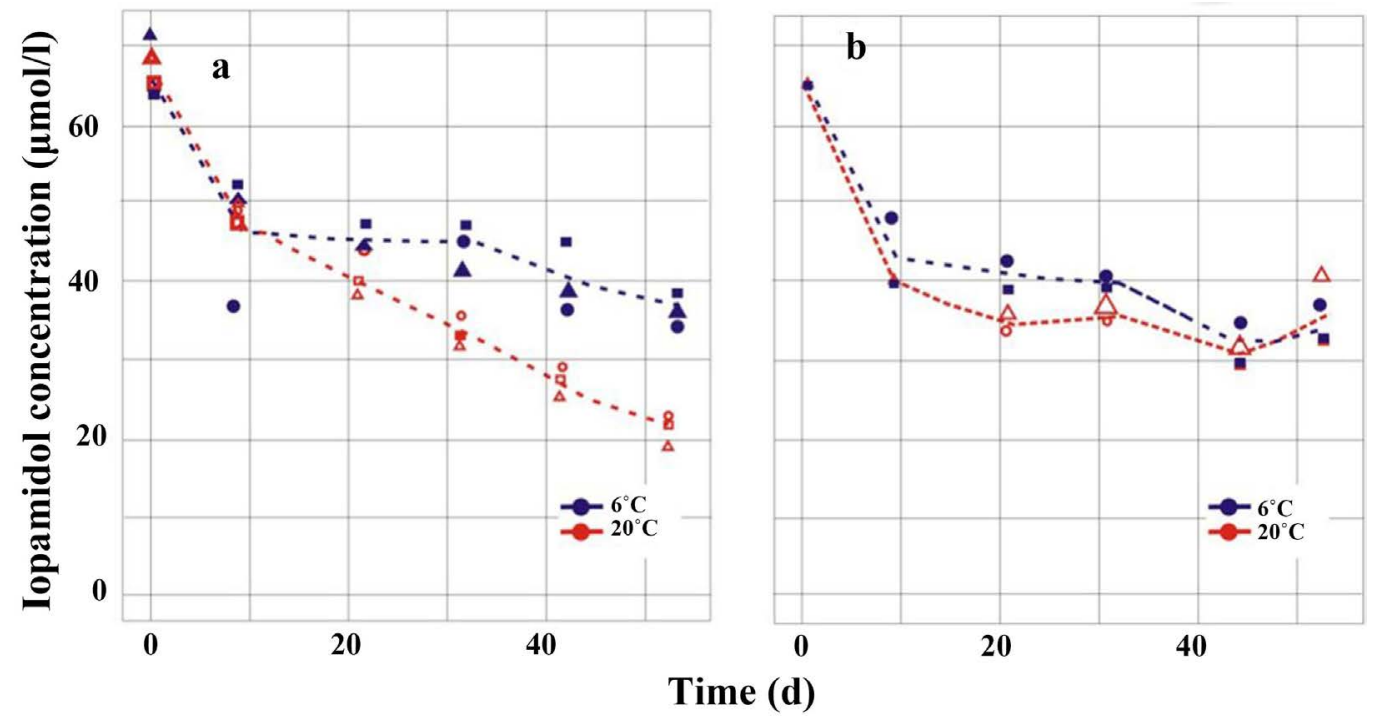

Figure 4. Iopamidol concentration in time at $6^{\circ} \mathrm{C}$ and $20^{\circ} \mathrm{C}$ with bGAC (a) and autoclaved GAC (b). Different symbols represent different replicates of the same treatment. Lines connect the mean value of replicates in each time point.

Literature reported from [24] [25] [26] accounts for similar variation between duplicate for example, an experiment involving 3 duplicates metformin biodegradation of $99 \%, 29 \%$ and $9 \%$ respectively, in the sludge pre exposed for a period of about 9 months to $1.5 \mathrm{mg} / \mathrm{L}$ metformin by activated sludge [27]. In this experiments duplicate bottles removed metformin to different degrees. ( $0 \%$ vs. $30 \%$ and $50 \%$ vs. $100 \%$ in two independent experiments). Proposition from the authors showed that the huge variation in the micro-pollutants removal rate, resulted from the diversity of microbial community in the inoculum, hence only the availability of specific degrades in the inoculum can bring about biodegradation of metformin. The experiments we carried out for analysis used biologically active granulated activated carbon (bGAC) in the inoculum present, although collecting similar samples of this mixture (inoculum having biologically active granulated activated carbon bGAC added) is not always easy therefore, the heterogeneous form of this mixture is used and this can tend to make the duplicates have different behaviors.

It is evident that temperature has varying effects on the adsorption activity of micro-pollutants and according to our research, two basic scenarios can be distinguished. The adsorption activity that occurs by exothermic reaction shows that temperature rise has an inverse relationship with the adsorption rate of micro-pollutants, and those adsorption activities that involve endothermic reaction shows that the adsorption rate of micro-pollutants has a direct relationship with temperature rise. Therefore, it is observed that when adsorption rate is inversely related to temperature rise as in case of the exothermic process, there is a fall in biodegradation activity of micro-pollutant and when adsorption activity of micro-pollutants is directly related to temperature as in the case of endothermic reaction, does not really ascertain biodegradation rate is high 
even though removal rate is high. This simply implies that for exothermic operating condition where temperature is negatively related with adsorption but positively related with biodegradation, removal rate is also high and biodegradation of micro-pollutants is also high, however, for the endothermic case where temperature is positively related with both adsorption rate and biodegradation, the removal rate is usually high however, biodegradation may or may not be high, so at an operating temperature of $20^{\circ} \mathrm{C}$ for exothermic condition, higher removal rate is a strong indication for micro-pollutants degradation as in the case of metformin and at $20^{\circ} \mathrm{C}$ in the case of endothermic process, higher removal rate does not ascertain higher micro-pollutants degradation. Therefore, at both temperature removals with both bGAC and autoclaved GAC combined give a trend indicating whether the compound is biodegraded or not as explained during iopromide degradation.

Deduction from our experimental observation and results accounted for a direct relationship between temperature and adsorption rate for iopromidol (Figure 4). As removal of iopamidol at $20^{\circ} \mathrm{C}$ using bGAC was higher than with autoclaved GAC, although at $6^{\circ} \mathrm{C}$ the removal rate and extent were even (Figure 4). On concluding, the experiments it was observed that $70 \%$ of the iopamidol was removed with bGAC and $45 \%$ of iopamidol was removed with autoclaved GAC and this removal took place at $20^{\circ} \mathrm{C}$ and this shows the biodegradation of iopamidol in autoclave GAC. Analysis with a peak of exact mass (within $6 \mathrm{ppm}$ ) and isotope pattern corresponding to biodegradation product of iopamidol as described by [28] was observed in experiment with bGAC cultivated at $20^{\circ} \mathrm{C}$, however, this is not so when cultivated at $6^{\circ} \mathrm{C}$, which in turn supports the proposition of iopamidol biodegradation. In other words, at $20^{\circ} \mathrm{C}$, it was observed that the removal with bGAC of iopamidol is higher, this could be correlated with the biodegradation of metformin and iopamidol. The driving force for the desorption of these compounds from bGAC comes from the biodegradation of dissolved fraction of metformin and iuopromide, releasing adsorption sites on the GAC surface, and hence contributing to the increased adsorption removal rate of iopamidol.

Analysis on diclofenac shows a higher removal rate with bGAC than with autoclaved GAC at both temperature this is totally different from deduction abstracted from iopamidol and iopromide. Hence to draw a conclusion on the biodegradation or adsorption of diclofenac onto bGAC seems difficult. Possible justification is that biodegradation of diclofenac occurred in bottles cultivated at both $6^{\circ} \mathrm{C}$ and $20^{\circ} \mathrm{C}$ with bGAC. Although at $6^{\circ} \mathrm{C}$, it is expected that the rate of biodegradation would not be significant enough to explain the observed removal. More so, peaks corresponding to diclofenac change over product were not found in any of these samples from day 54 in either temperature. Therefore, clarifying biodegradation as an additional removal mechanism for diclofenac with bGAC could not be achieved.

Figure 5 shows the graph of Diclofenac concentration in time at $6^{\circ} \mathrm{C}$ and $20^{\circ} \mathrm{C}$ with bGAC in (a) and autoclaved GAC in (b). 


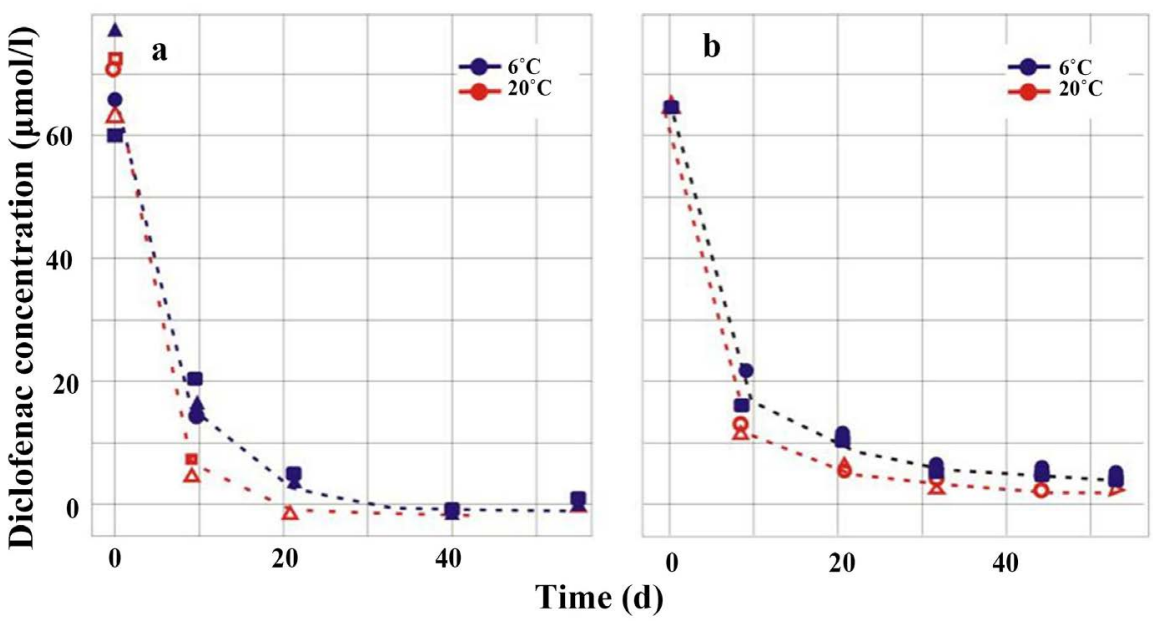

Figure 5. Diclofenac concentration in time at $6^{\circ} \mathrm{C}$ and $20^{\circ} \mathrm{C}$ with bGAC (a) and autoclaved GAC (b). Different symbols represent different replicates of the same treatment. Lines connect the mean value of replicates in each time point.

\subsection{The Effect Temperature on Adsorption of Non-Biodegraded Micro-Pollutants}

Chemical adsorption process has the advantage to remove non-biodegradable micro-pollutants from waste water. Drawback may set in, which is the conventional adsorption process in the design process of the absorbents.

Different types of adsorbent materials can only remove one particular group of pollutants. In most researches carbon adsorbents have been particularly suitable for pharmaceutical pollutants removal. Furthermore macro-porous adsorption resin (MAR) was used in removing adsorbing soluble microbial products (SMP) over the years.

Observation shows no possible trends indicating biodegradation of the micro pollutants with bGAC, so adsorption was the only removal mechanism applicable both with bGAC as well as autoclaved GAC whose results were the basis to evaluate the effect of temperature on adsorption of these micro pollutants at different concentrations.

At $6^{\circ} \mathrm{C}$ for both bGAC and GAC melamine and metformin was removed to a larger extent than at $20^{\circ} \mathrm{C}$ as presented in Figure 6 and Figure 7 respectively. The indication was that adsorption of melamine is exothermic. This can be analyzed on the increased coverage of the GAC surface at increasing micro-pollutant initial concentrations. [29] [30] showed that at higher GAC coverage, the temperature dependence of adsorption is reduced, which is related to the site (pores) with varying adsorption affinities on the surface of activated carbon. From observation the sites with high affinity are the first to be occupied by the adsorbate and temperature will be higher in those sites, while low affinity sites are accommodated only at higher AC surface and site temperature dependence is negligible [31] At an intial concentration of $70 \mu \mathrm{M}$, melamin was captured to a larger extent at $6^{\circ} \mathrm{C}$ than at $20^{\circ} \mathrm{C}$ with autoclaved GAC only. At this junction is it important to note that autoclaving of the activated carbon might have affected the 

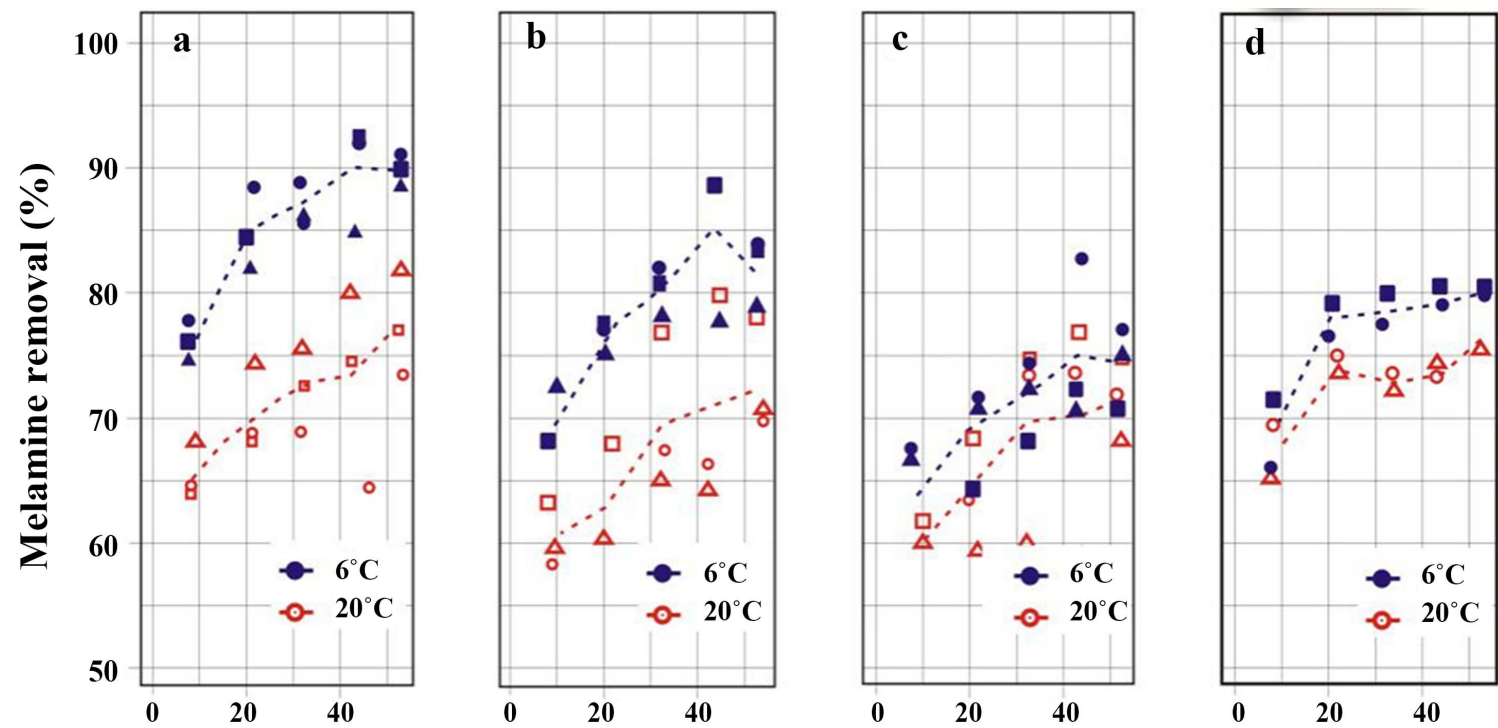

Time (d)

Figure 6. Melamine removal with bGAC at 3 different initial concentrations - (a) $26 \mu \mathrm{M}$, (b) $46 \mu \mathrm{M}$, (c) $70 \mu \mathrm{M}$ - and autoclaved GAC - (d) $70 \mu \mathrm{M}$ - at $6^{\circ} \mathrm{C}$ and $20^{\circ} \mathrm{C}$. Different symbols represent different replicates of the same treatment. Lines connect the mean value of replicates in each time point. Y-axis scale runs from $50 \%-100 \%$ for better visualization of the data.
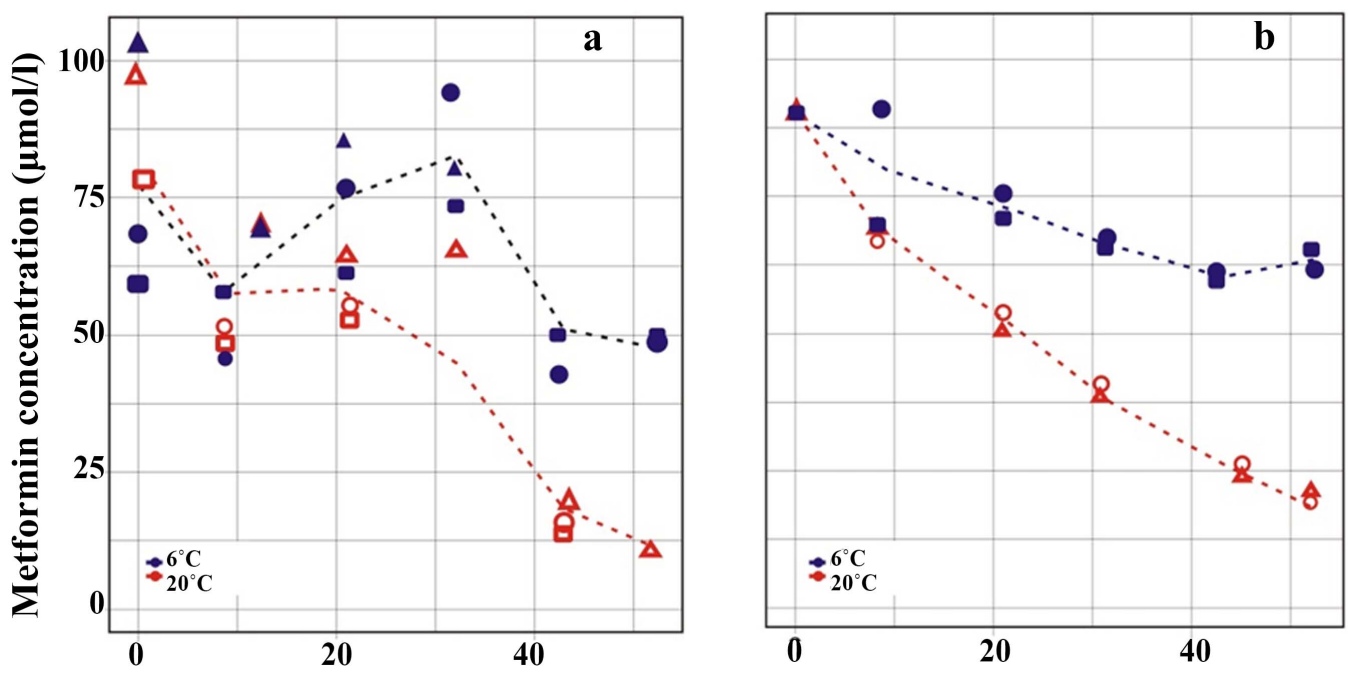

Time (d)

Figure 7. Metformin concentration in time at $6^{\circ} \mathrm{C}$ and $20^{\circ} \mathrm{C}$ with bGAC (a) and autoclaved GAC (b). Different symbols represent different replicates of the same treatment. Lines connect the mean value of replicates in each time point.

biofilm or organic matter adsorbed previously unto activated carbon and reducing it coverage.

There was no difference in benzotriazole removal within the temperatures observed (neither with bGAC nor with GAC autoclaved), indication shows that this compound was not bio-degraded and that temperature does not affect adsorption to an extent. In these research benzotriazole, iopamidol and melamine 
were not biodegraded with bGAC, even though their biodegradation has been reported in literatures [32] [33] [34] [35].

Moreover, we propose that experiments associated with micro-pollutants removal using activated carbon at different temperatures can be used to checkmate the micro-pollutants biodegradability by bGAC.

\subsection{The Activity of Adsorption on Used and Fresh GAC}

The used and fresh GAC adsorption capacity was compared by comparing the micro-pollutants removal of fresh GAC with MP removal by bGAC (initial concentration $70 \mu \mathrm{M}$ ) on the 9th day. We make this comparison so as to get insight to the possible loss of adsorption capacity due to GAC utilized. More than $90 \%$ removal was achieved for 5 out of 7 compounds, despite their hydropholic character of these micro-pollutants, as shown in their $\log D_{o w}$ (Table 1$)$.

The following are the list of micro-pollutant removal by used and fresh GAC at $6^{\circ} \mathrm{C}$ and relative removal of used and fresh GAC and used/fresh GAC. Values correspond to mean of triplicates for used GAC and duplicates for fresh GAC; benzotriazole (fresh GAC 98\%, used GAC 84\%, used/fresh GAC 85\%), diclofenac (fresh GAC 96\%, used GAC 75\%, used/fresh GAC 78\%), guanylurea (fresh GAC 54\%, used GAC 79\%, used/fresh GAC 150\%), iopamidol ( used GAC 91\%, fresh GAC 31\%, used/fresh GAC 34\%), iopromide ( fresh GAC 93\%, used GAC $35 \%$, used/fresh GAC 38\%), melamine (fresh GAC 94\%, used GAC 63\%, used/fresh GAC 67\%) and metformin (fresh GAC 12\%, used GAC 30\%, used/fresh GAC 250\%)

\section{Conclusions}

Analysis backed up with experimental evidence observed in this study, shows that the growth of biofilm in the granulated activated carbon (GAC) filter at a drinkable water treatment plant (DWTP) has a great tendency of biodegrading iopromide, metformin, and iopamidol. More so, results from this study show that temperature has a direct relationship to the adsorptive activity of iopromide, iopamidol, diclofenac. However, the relationship of temperature with adsorptive activity of guanylurea, melamine and metformin is positively correlated. Also,

Table 1. Micro-pollutants, $\log D_{\text {ow }}$ and molecular weight values.

\begin{tabular}{ccc}
\hline Micro-pollutant & $\log D_{O W}$ at $\mathrm{pH} 7.0^{1}$ & Molecular weight $(\mathrm{g} / \mathrm{mol})$ \\
\hline Benzotriazole & 1.33 & 120 \\
Diclofenac & 1.39 to 3.2 & 298 \\
Guanylurea & -2.08 & 104 \\
Iopamidol & -2.6 & 779 \\
Iopromide & -2.3 & 793 \\
Melamine & -2.2 & 128 \\
Metformin & -4.2 to -3.4 & 131 \\
\hline
\end{tabular}


we were able to deduce that the adsorption potential of the granulated activated carbon used for more than 50,000 bed volumes can be basically compared to adsorption of the contribution of biodegradation as a process of removing micro-pollutants from the granulated activated carbon filter during drinking water production. Additionally, this research gives extended views related to bio regeneration of loaded granulated activated carbon (GAC). Finally, this research shows and explains that both adsorption and biodegradation take place concurrently enough to meet the needs of removing micro-pollutants from water, thereby, leading to an effective and fruitful bio regeneration of the granulated activated carbon (GAC) and hence help reduce thermal recreation and regeneration that is actively used for granulated activated carbon filters at drinking water treatment plants (DWTP) of fresh granulated activated carbon for diclofenac and benzotrriazole and although higher for guanylurea and metformin.

Furthermore, the experimental method adopted in checking into the correlation and differences in the adsorption and biodegradation technique of micro-pollutants removal by granulated activated carbon at different temperature proved very pivotal and in turn showed the great significance of using the adsorption technique and biodegradation. The differences that arise between these methods of micro-pollutants removal, help to shed more light to the potential and activity of the growth of the biofilm in the granulated activated carbon filter to breakdown the micro-pollutants into simpler units and to clarify the contribution of biodegradation as a removal process for micro-pollutants in these filters during drinking water production.

\section{Acknowledgements}

This work was financially supported by Mega Integrated Resources limited, Nigeria. We want to thank Professor L. A. Jimoda for his professional support and advice during this research and thanks are so little to show our sincere appreciation to the CEO of Mega Integrated Resources limited for financing this project design, and for sharing insight and conclusion of intra-variability of experimental replicates and finally proofreading the manuscript.

\section{Conflicts of Interest}

The authors declare that they have no known competing financial interests or personal relationships that could have appeared to influence the work reported in this paper.

\section{References}

[1] Altmann, J., Rehfeld, D., Trader, K., Sperlich, A. and Jekel, M. (2016) Combination of Granular Activated Carbon Adsorption and Deep-Bed Filtration as a Single Advanced Wastewater Treatment Step for Organic Micropollutant and Phosphorus Removal. Water Research, 92, 131-139. https://doi.org/10.1016/j.watres.2016.01.051

[2] Briones, R.M. and Sarmah, A.K. (2018) Detailed Sorption Characteristics of the Anti-Diabetic Drug Metformin and Its Transformation Product Guanylurea in Agri- 
cultural Soils. Science of the Total Environment, 630, 1258-1268.

https://doi.org/10.1016/j.scitotenv.2018.02.306

[3] Çeçen, F. and Aktaş, Ö. (2012) Activated Carbon for Water and Wastewater Treatment: Integration of Adsorption and Biological Treatment. WILEY-VCH Verlag GmbH \& Co. KGaA, Weinheim. https://doi.org/10.1002/9783527639441

[4] El-Sayed, W.S., El-Baz, A.F. and Othman, A.M. (2006) Biodegradation of Melamine Formaldehyde by Micrococcus sp. Strain MF-1 Isolated from Aminoplastic Wastewater Effluent. International Biodeterioration \& Biodegradation, 57, 75-81. https://doi.org/10.1016/j.ibiod.2005.11.006

[5] Grandclément, C., Seyssiecq, I., Piram, A., Wong-Wah-Chung, P., Vanot, G., Tiliacos, N., Roche, N. and Doumenq, P. (2017) From the Conventional Biological Wastewater Treatment to Hybrid Processes. The Evaluation of Organic Micropollutant Removal: A Review. Water Research, 111, 297-317.

https://doi.org/10.1016/j.watres.2017.01.005

[6] Greenstein, K.E., Lew, J., Dickenson, E.R.V. and Wert, E.C. (2018) Investigation of Bio-Transformation, Sorption, and Desorption of Multiple Chemical Contaminants in Pilot-Scale Drinking Water Biofilters. Chemosphere, 200, 248-256.

https://doi.org/10.1016/j.chemosphere.2018.02.107

[7] Gupta, V.K., Gupta, B., Rastogi, A., Agarwal, S. and Nayak, A. (2011) Pesticides Removal from Waste Water by Activated Carbon Prepared from Waste Rubber Tire. Water Research, 45, 4047-4055. https://doi.org/10.1016/j.watres.2011.05.016

[8] Han, N., Reinhard, M., Khan, E., Chen, H., Tung, V., Li, Y., Giek, S., Nguyen, Q.B., Saeidi, N. and Gin, K.Y. (2019) Emerging Contaminants in Wastewater, Stormwater Runoff, and Surface Water: Application as Chemical Markers for Diffuse Sources. Science of the Total Environment, 676, 252-267. https://doi.org/10.1016/j.scitotenv.2019.04.160

[9] Herzog, B., Lemmer, H., Huber, B., Horn, H. and Müller, E. (2014) Xenobiotic Benzotriazoles-Biodegradation under Meso- and Oligotrophic Conditions as Well as Denitrifying, Sulfate-Reducing, and Anaerobic Conditions. Environmental Science and Pollution Research, 21, 2795-2804. https://doi.org/10.1007/s11356-013-2199-3

[10] Hindarso, H., Ismadji, S., Wicaksana, F. and Indraswati, N. (2001) Adsorption of Benzene and Toluene from Aqueous Solution onto Granular Activated Carbon. Journal of Chemical \& Engineering Data, 46, 788-791. https://doi.org/10.1021/je000176g

[11] Kiss, A. and Fries, E. (2009) Occurrence of Benzotriazoles in the Rivers Main, Hengstbach, and Hegbach (Germany). Environmental Science and Pollution Research, 16, 702-710. https://doi.org/10.1007/s11356-009-0179-4

[12] Klimenko, N.A., et al. (2010) Influence of Sodium Azide on the Removal of Fulvic Acids by Activated Carbon. Journal of Water Chemistry and Technology, 32, 329-335. https://doi.org/10.3103/S1063455X10060032

[13] Kormos, J.L., Schulz, M., Kohler, H.P.E. and Ternes, T.A. (2010) Biotransformation of Selected Iodinated X-Ray Contrast Media and Characterization of Microbial Transformation Pathways. Environmental Science \& Technology, 44, 4998-5007. https://doi.org/10.1021/es1007214

[14] Kosjek, T., Heath, E., Pérez, S. and Petrovic, M. (2009) Metabolism Studies of Diclofenac and Clofibric Acid in Activated Sludge Bioreactors Using Liquid Chromatography with Quadrupole Time-of-Flight Mass Spectrometry. Journal of Hydrolo$g y, 372,109-117$. https://doi.org/10.1016/j.jhydrol.2009.04.006

[15] Margot, J., Kienle, C., Magnet, A., Weil, M., Rossi, L., de Alencastro, L.F., Abegglen, 
C., Thonney, D., Chèvre, N., Schärer, M. and Barry, D.A. (2013) Treatment of Micro-Pollutants in Municipal Wastewater: Ozone or Powdered Activated Carbon? Science of the Total Environment, 461-462, 480-498. https://doi.org/10.1016/j.scitotenv.2013.05.034

[16] Markiewicz, M., Jungnickel, C., Stolte, S., Białk-Bielińska, A., Kumirska, J. and Mrozik, W. (2017) Ultimate Biodegradability and Ecotoxicity of Orally Administered Antidiabetic Drugs. Journal of Hazardous Materials, 333, 154-161. https://doi.org/10.1016/j.jhazmat.2017.03.030

[17] Markiewicz, M., Jungnickel, C., Stolte, S., Białk-Bielińska, A., Kumirska, J. and Mrozik, W. (2017) Primary Degradation of Antidiabetic Drugs. Journal of Hazardous Materials, 324, 428-435. https://doi.org/10.1016/j.jhazmat.2016.11.008

[18] Moreno-Castilla, C. (2004) Adsorption of Organic Molecules from Aqueous Solutions on Carbon Materials. Carbon, 42, 83-94.

https://doi.org/10.1016/j.carbon.2003.09.022

[19] Oh, S., Hammes, F. and Liu, W. (2018) Metagenomic Characterization of Biofilter Microbial Communities in a Full-Scale Drinking Water Treatment Plant. Water Research, 128, 278-285. https://doi.org/10.1016/j.watres.2017.10.054

[20] Piai, L., Dykstra, J.E., Adishakti, M.G., Blokland, M., Langenhoff, A.A.M. and van der Wal, A. (2019) Diffusion of Hydrophilic Organic Micropollutants in Granular Activated Carbon with Different Pore Sizes. Water Research, 162, 518-527. https://doi.org/10.1016/j.watres.2019.06.012

[21] Mompelat, S., Le Bot, B. and Thomas, O. (2009) Occurrence and Fate of Pharmaceutical Products and By-Products, from Resource to Drinking Water. Environment International, 35, 803-814. https://doi.org/10.1016/j.envint.2008.10.008

[22] Poursat, B.A.J., van Spanning, R.J.M., Braster, M., Helmus, R., de Voogt, P. and Parsons, J.R. (2019) Biodegradation of Metformin and Its Transformation Product, Guanylurea, by Natural and Exposed Microbial Communities. Ecotoxicology and Environmental Safety, 182, Article ID: 109414. https://doi.org/10.1016/j.ecoenv.2019.109414

[23] Müller, J., Jewell, K.S., Schulz, M., Hermes, N., Ternes, T.A., Drewes, J.E. and Hübner, U. (2019) Capturing the Oxic Transformation of Iopromide-A Useful Tool for an Improved Characterization of Predominant Redox Conditions and the Removal of Trace Organic Compounds in Biofiltration Systems? Water Research, 152, 274-284. https://doi.org/10.1016/j.watres.2018.12.055

[24] Reungoat, J., Macova, M., Escher, B.I., Carswell, S., Mueller, J.F. and Keller, J. (2010) Removal of Micropollutants and Reduction of Biological Activity in a Full Scale Reclamation Plant Using Ozonation and Activated Carbon Filtration. Water Research, 44, 625-637. https://doi.org/10.1016/j.watres.2009.09.048

[25] Ruff, M., Mueller, M.S., Loos, M. and Singer, H.P. (2015) Quantitative Target and Systematic Non-Target Analysis of Polar Organic Micro-Pollutants along the River Rhine Using High-Resolution Mass-Spectrometry-Identification of Unknown Sources and Compounds. Water Research, 87, 145-154. https://doi.org/10.1016/j.watres.2015.09.017

[26] Sander, M. and Pignatello, J.J. (2005) Characterization of Charcoal Adsorption Sites for Aromatic Compounds: Insights Drawn from Single-Solute and Bi-Solute Competitive Experiments. Environmental Science \& Technology, 39, 1606-1615. https://doi.org/10.1021/es0491351

[27] Schulz, M., Löffler, D., Wagner, M. and Ternes, T.A. (2008) Transformation of the X-Ray Contrast Medium Iopromide in Soil and Biological Wastewater Treatment. 
Environmental Science \& Technology, 42, 7207-7217. https://doi.org/10.1021/es800789r

[28] Pikaar, I., Koelmans, A.A. and Noort Van, P.C.M. (2006) Sorption of Organic Compounds to Activated Carbons. Evaluation of Isotherm Models. Chemosphere, 65, 2343-2351. https://doi.org/10.1016/j.chemosphere.2006.05.005

[29] Shimabuku, K.K., Paige, J.M., Luna Agüero, M. and Summers, R.S. (2017) Simplified Modeling of Organic Contaminant Adsorption by Activated Carbon and Biochar in the Presence of Dissolved Organic Matter and Other Competing Adsorbates. Environmental Science \& Technology, 51, 10031-10040.

https://doi.org/10.1021/acs.est.7b00758

[30] Stackelberg, P.E., Gibs, J., Furlong, E.T., Meyer, M.T., Zaugg, S.D. and Lippincott, R.L. (2007) Efficiency of Conventional Drinking-Water-Treatment Processes in Removal of Pharmaceuticals and Other Organic Compounds. Science of the Total Environment, 377, 255-272. https://doi.org/10.1016/j.scitotenv.2007.01.095

[31] Taghdiri, N. and Zamani, M. (2013) Hexamine Adsorption Study on Activated Carbon from Aqueous Solutions for Application in Treatment of Hexamine Industrial Wastewater. International Journal of Environmental Science and Technology, 10, 19-26. https://doi.org/10.1007/s13762-012-0102-2

[32] Ternes, T.A., Meisenheimer, M., McDowell, D., Sacher, F., Brauch, H.-J., Haist-Gulde, B., Preuss, G., Wilme, U. and Zulei-Seibert, N. (2002) Removal of Pharmaceuticals during Drinking Water Treatment. Environmental Science \& Technology, 36, 3855-3863. https://doi.org/10.1021/es015757k

[33] Tisler, S. and Zwiener, C. (2019) Aerobic and Anaerobic Formation and Biodegradation of Guanylurea and Other Transformation Products of Metformin. Water Research, 149, 130-135. https://doi.org/10.1016/j.watres.2018.11.001

[34] Ternes, T. (2007) The Occurrence of Micopollutants in the Aquatic Environment: A New Challenge for Water Management. Water Science and Technology, 55, 327-332. https://doi.org/10.2166/wst.2007.428

[35] Starling, M.C.V.M., Amorim, C.C. and Leão, M.M.D. (2019) Occurrence, Control and Fate of Contaminants of Emerging Concern in Environmental Compartments in Brazil. Journal of Hazardous Materials, 372, 17-36.

https://doi.org/10.1016/j.jhazmat.2018.04.043 